\title{
Proof-of-concept projects proving productive
}

Published at www.cmaj.ca on Nov. 2

I t's a classic Catch-22 scenario. A group needs funding to implement an innovative idea with the potential to save many lives. But the group first needs to show that their proposed project will saves lives before anyone will agree to fund it. One possible alternative to this conundrum is to fund the best ideas even if evidence of their efficacy doesn't yet exist — but only fund them for a short period.

"The idea of having small projects of short duration, based on results, is becoming popular," Dr. I.D. Rusen, director of the Tuberculosis Control and Prevention Department of the International Union Against Tuberculosis and Lung Disease, told delegates to the Oct. 25-28 Canadian Conference on International Health in Ottawa, Ontario.

Rusen has been involved in many short-term "proof of concept" projects through the Fund for Innovative DOTS (Directly Observed Treatment, Short-course) Expansion Through Local Initiatives to Stop TB (FIDELIS). This initiative, funded by the Canadian International Development Agency, was created in 2003 to rapidly implement novel and innovative means of finding and curing new cases of tuberculosis.

It was estimated in 2003 that only $45 \%$ of the world's cases of tuberculosis were detected. The World Health Organization, which declared tuberculosis a global public health emergency in 1993, has set a case detection target of $70 \%$. Inexpensive, short-term projects to increase case detection are an important part of achieving that target, says Rusen.

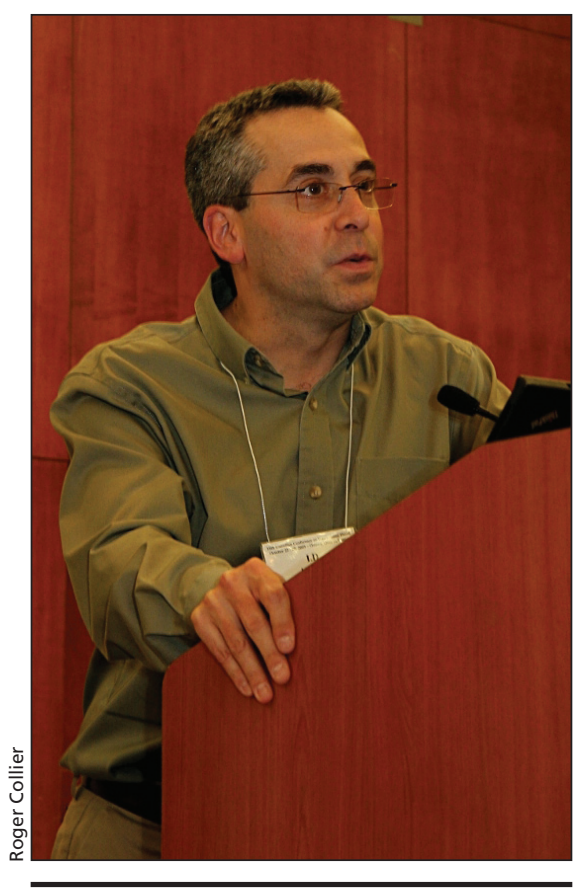

Small, short-term projects can provide long-term benefits in the battle against tuberculosis in developing countries, says Dr. I.D. Rusen, director of the Tuberculosis Control and Prevention Department of the International Union Against Tuberculosis and Lung Disease.

Since its inception, FIDELIS has funded 51 projects in 18 countries, mostly in regions with the highest burden of tuberculosis. These projects range from training school children in China how to detect possible tuberculosis cases in their families to creating a radio call-in show in Pakistan for tuberculosis patients to explain how they were diagnosed and treated. So far, the projects have resulted in the detection of 272216 new cases of tuberculosis.
The Canadian government has invested \$32 million in the FIDELIS initiative. Each project has a budget between US\$150000 and US\$250 000 . So if a project fails, not much money has been lost. If successful, a project can be extended, though a contract lasts only a year. But that short-term investment can yield long-term rewards, says Rusen. "If you are successful, you should be able to move on to long-term projects. In China, some projects were so successful in one year that they resulted in new countrywide policies."

In an article in the American Journal of Public Health, Rusen and a colleague wrote that the FIDELIS model was an efficient means of increasing tuberculosis case detection in a short time and has helped a wide range of target populations (AJPH 2006;96:14-6). They also suggested that it "may be appropriate for addressing other perplexing global public health problems."

Because they are short in duration, the projects concentrate on local solutions to increase the detection of tuberculosis. So even if funding is not extended beyond a year, the countries will have local expertise and can incorporate any new services into its health care system. Of course, not all countries are equal in infrastructure and resources, so the long-term effects vary widely from project to project. And sometimes one year is just not long enough.

"In some African cities, one year was too difficult of a time frame for those settings," said Rusen. "I think we will do a few things differently next time." - Roger Collier, CMAJ

DOI:10.1503/cmaj.109-3092 